\title{
Malate Dehydrogenase, Mitochondrial
}

National Cancer Institute

\section{Source}

National Cancer Institute. Malate Dehydrogenase, Mitochondrial. NCI Thesaurus. Code C124985.

Malate dehydrogenase, mitochondrial (338 aa, $\sim 36 \mathrm{kDa}$ ) is encoded by the human MDH2 gene. This protein plays a role in the conversion of malate to oxaloacetate. 